\title{
Original article \\ Perception of Genital Cancer among Women attending the OPD of Tertiary Care Hospital in Old part of Dhaka City
}

\author{
Nasreen Sultana ${ }^{1}$, Hosne Ara Begum ${ }^{2}$, Najmun Nahar ${ }^{3}$ Asma Jesmin $^{4}$, Ismat Ara ${ }^{5}$, Hasina \\ Emroz Mallick $^{6}$, Anika Tasnim ${ }^{7}$
}

\begin{abstract}
${ }^{1}$ Assistant Professor, Dept. of Obstetrics \& Gynaecology, Dhaka National Medical College, ${ }^{2}$ Professor \& Head of the Dept. of of Obstetrics \& Gynaecology, Dhaka National Medical College, ${ }^{3}$ Resident surgeon, Dept.of Obstetrics \& Gynaecology, Dhaka National Medical College Hospital, ${ }^{4}$ Resident surgeon, Dept.of Obstetrics \& Gynaecology, Dhaka National Medical College Hospital, ${ }^{5}$ Senior Medical Officer, Dept.of Obstetrics \& Gynaecology, Dhaka National Medical College Hospital, ${ }^{6}$ Senior Medical Officer, Dept.of Obstetrics \& Gynaecology, Dhaka National Medical College Hospital, ${ }^{7}$ Student(Masters), Dept. of Statistics, Dhaka University
\end{abstract}

\begin{abstract}
:
Genital cancer is increasing day by day in Bangladesh. Among those cervical cancer is the most common constituting about $22-29 \%$ throughout the country. Breast cancer is the second most common cause and it is about $13-17 \%$ of the female cancer. In Bangladesh, risk factors for cervical cancer are related to early marriage, early sexual activities, multiparity, STD,s and low socioeconomic condition. Lack of knowledge about the risk factors is also an important determinant behind the incidence of these cancers. With the objectives to assess whether they can mention the name of female genital cancer and risk factors for those cancers, this study was conducted. Methodology: This was a prospective observational study. Total 297 women attending the outpatient department of obstetrics and Gynaecology Unit of Dhaka National Medical College Hospital were interviewed with a preset questionnaire during a period of January to March 2009.Results: About $85.8 \%$ of women could mention that they had heard of genital cancers. Among those they mentioned the name of uterus (65\%), cervix (5.5\%) and breast $(\mathbf{2 9 . 5 \%})$. None of them could mention ovarian or other genital cancers. Among them only $\mathbf{1 9 . 2 \%}$ mentioned the risk factors. Risk factors they mentioned were genital infection $(15.79 \%)$, OCP $(21.93 \%)$, multiple sexual partners $(10.53 \%)$, white discharge $(21.93 \%)$, repeated MR $(12.28 \%)$, many children in early age $(8.77 \%)$, no breast feeding $(8.77 \%)$. They heard of cancer from various sources such as media $(\mathbf{4 3 . 1 4 \%})$, relative $(30.20 \%)$, doctors and other service providers $(\mathbf{1 8 . 8 0 \%})$, patients $(5.90 \%)$ and book $(1.96 \%)$. This study found that majority of women know about the genital cancer and all of them were eager to learn more about genital cancers and their prevention. Cervical and breast cancer screening program is started in Bangladesh. There is also media campaign. Awareness development, supervised screening set up and monitoring can reduce the preventable genital cancers in our country.
\end{abstract}

\section{Introduction:}

Cancer is one of the major causes of morbidity and mortality among non communicable diseases in Bangladesh and all over the world.

The genital tract is the primary site of the cancer in $14 \%$ of cases. This figure is made up as uterus- 8 percent, ovary 5 percent, vulva and vagina 1 percent. Malignant disease of the ovary formerly regarded as not so important, now accounts for 50-55 percent deaths due to genital cancers ${ }^{1}$.

In developed countries most common cause of cancer in women is breast cancer. Cervical cancer is the second most common cause. In developing countries, cancer of the cervix is still the commonest followed by ovarian cancer.

Approximately $80 \%$ of cervical cancers occur in developing countries ${ }^{2}$.
Worldwide, cervical cancer is twelfth most common cause and fifth most deadly cancer in women $^{3,4}$

In Bangladesh genital cancer is increasing day by day and there is no population based data about its magnitude. Among those cervical cancer is the most common constituting about 22-29\% (from hospital based data) throughout the country. Annual incidence of cervical cancer is 11956 . About $80 \%$ women come for treatment in advanced stage. Breast cancer is the second most common cause and it is about $13-17 \%$ of the female cancer ${ }^{5}$.

Bangladesh Government has taken programmatic steps towards controlling cervical cancer by developing cervical cancer screening program. Also various development partners and NGO's are working in this field. There is media campaign for awareness development. 
With this background this study was conducted to assess whether the women could mention the names of female genital cancers and there sites and to evaluate whether they could cite the risk factors for those cancers.

\section{Methodology:}

This was a prospective observational study. Data were collected randomly by using a structured questionnaire from the patients attending the outpatient department of Obstetrics and Gynaecology of Dhaka National Medical College Hospital. It was conducted during the period from January to March 2009. A total of 297 women were interviewed. The preset questionnaire included, sociodemographic profile, whether they heard of genital cancers, site of cancers, risk factors, sources of their information.

\section{Result:}

Among the two hundred ninety seven women majority $(65.32 \%)$ was between $21-40$ years of age, $19.86 \%$ was above 40 years of age group and the rest (14.82) was below 20 years of age. About $18.18 \%$ was illiterate, $66.33 \%$ received education upto SSC level and $15.49 \%$ received HSC and above level (Chart.-1). Majority $(93.5 \%)$ were married, $3.3 \%$ and $3.2 \%$ were widow and unmarried respectively.

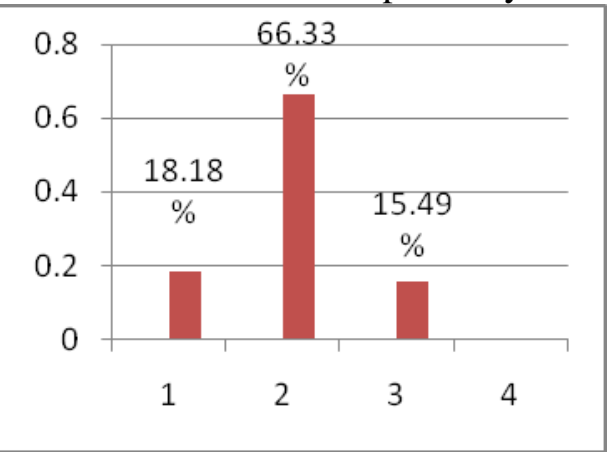

Chart-1showing educational status of the participants

About 255 (85.8\%) of women could mention that they had heard of genital cancers (fig.-1).

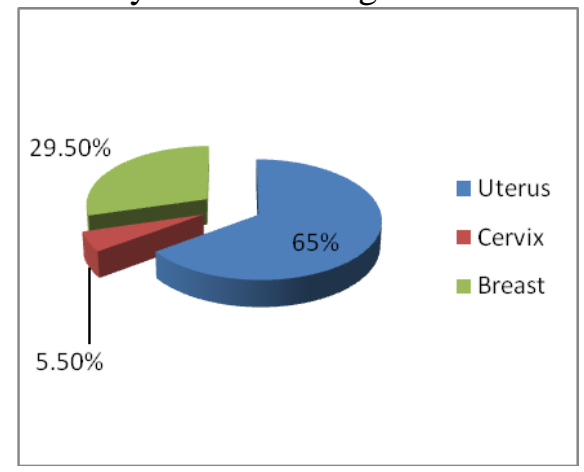

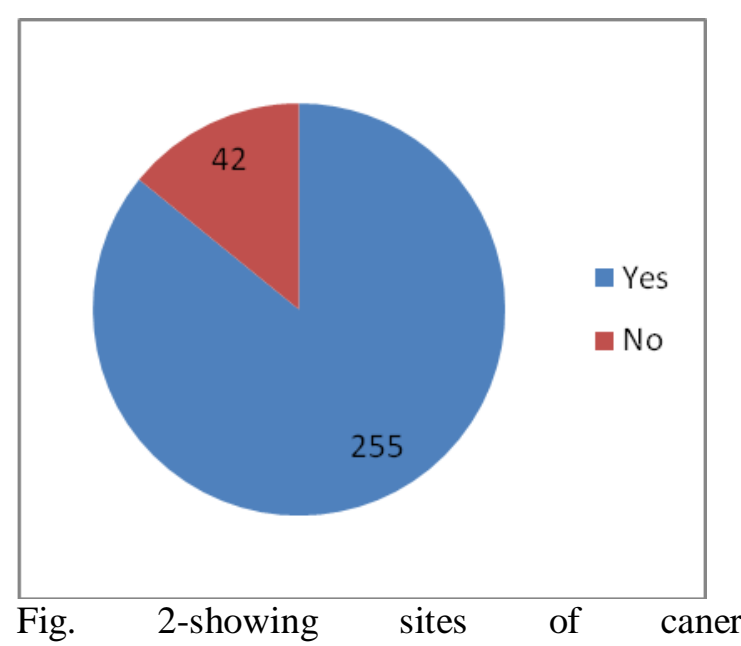

Fig.-1 Showing number of participants

mentioning about genital cancer

Among those they mentioned the name of uterus $(65 \%)$, cervix $(5.5 \%)$ and breast $(29.5 \%)$ (fig.-2). None of them could mention ovarian or other genital cancers. Among them only $19.2 \%$ mentioned the risk factors.

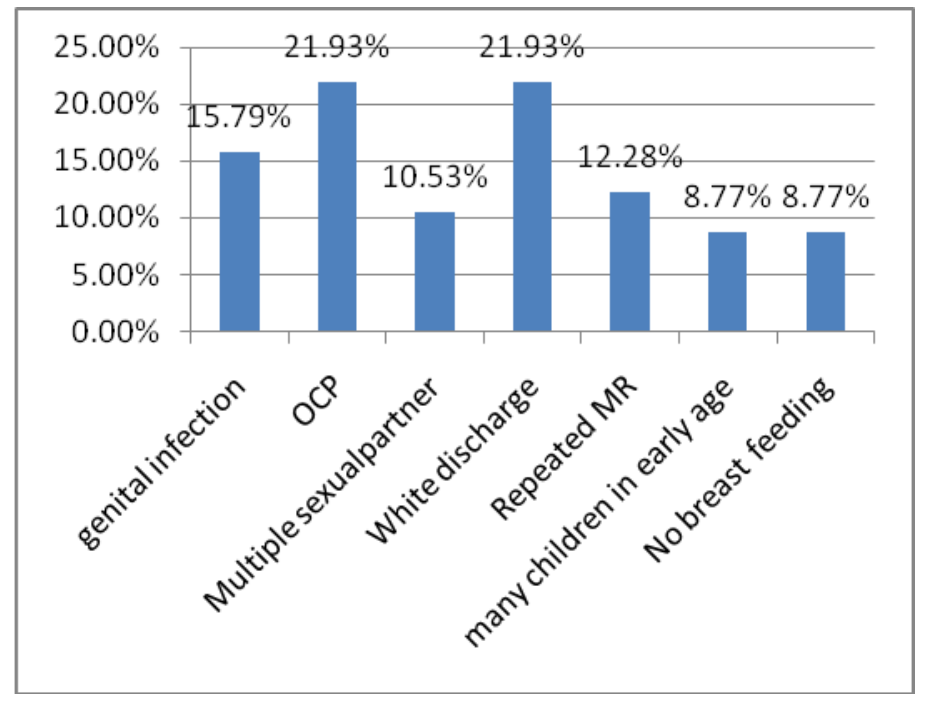

Chart-2 Showing the risk factors as mentioned by them

Risk factors were mentioned as genital infection (15.79\%), OCP (21.93\%), multiple sexual partners $(10.53 \%)$, white discharge (21.93\%), repeated MR (12.28\%), many children in early age (8.77\%), no breast feeding $(8.77 \%)$ (Chart-2).

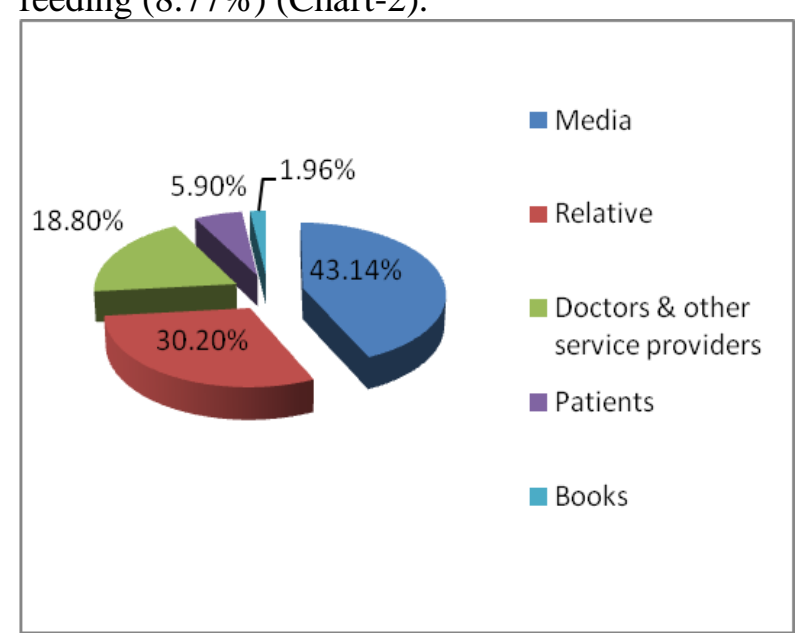

Fig.-3 showing the sources of information 
They heard of cancer from various sources such as media $(27.2 \%)$, relative $(26.1 \%)$, doctors and other service providers $(12.3 \%)$, patients (5.2\%) and book (1.6\%) (Fig.-3).

\section{Discussion:}

In this study 297 women attending the outpatient department of obstetrics and gynaecology of Dhaka National Medical College and Hospital, were interviewed with a view in mind to assess their perception about genital cancers and their risk factors.

The majority of the respondents mentioned the names of genital cancers. But a small portion could mention the risk factors. Though they mentioned the name of uterus mostly but none of them could mention the ovarian cancer. Media (television) was mentioned as the prime source. There is advertisement in the television on cervical cancer. It becomes as uterine cancer in their local language.Educated women could mention the names more than the illiterate women.

Another objective of this study was to obtain their perception on risk factors or causes. Only few were conversant with the risk factors such as genital infection, multiple sexual partners, too many children in early age, no breast feeding.

The American Cancer Society provided list of risk factors: HPV infection, smoking, HIV infection, Chlamydia infection, stress and stress related disorders, dietary factors, hormonal contraception multiple pregnancies, exposure to diethylstillbesterol and a family history of cervical cancer ${ }^{6,11,12,13,14}$. Human papillomavirus (HPV) infection with high risk types 16, 18 has been shown to be a necessary factor in the development of cervical cancer of $70 \%$ of cervical cancer ${ }^{7}$.

In Bangladesh, risk factors for cervical cancer are related to early marriage, early sexual activities, multiparity, STD,s and low socioeconomic condition. Lack of knowledge about the risk factors is also an important determinant behind the incidence of these cancers.

Cervical cancer is a type of cancer which can be identified in its precancerous form and it takes a long time to be in malignant form. If cancer cervix is treated in its precancerous form successfully the lesions do not develop into invasive cancer.

Cervical cancer screening based on VIA (Visual inspection with acetic acid) method is going on in 16 districts and 12 unions. The colposcopy clininic of BSMMU, DMCH and $\mathrm{CMCH}$ are receiving VIA+ve referred cases from selected areas. From November 2004 to November 2005 VIA test were done at service points of 16 districts. Among the 548 (4.92\%) were VIA +ve and were referred. Of the referred cases, 257(46.9\%) of VIA +ve women attended BSMMU colposcopy clinic till November 2005. Out of them 112(43.6\%) had CIN or cervical cancer ${ }^{8}$.

According to WHO, In each year about 12900 women are getting cervical cancer, among them approximately 6561 women die. Eighteen women are dying of cancer cervix each day. Cervical cancer screening program is established in developed countries. Cervical cancer deaths decreased by $74 \%$ in the last 50 years largely due to widespread pap smear screening ${ }^{3}$.

According to the US National cancer Institute's 2005 Health Information National Trends Survey, only $40 \%$ of American women surveyed had heard of human papilloma virus infection \& $20 \%$ had hear of its linkage to cervical cancer ${ }^{9}$.

To prevent genital cancer the women as well as other family member should know the ways of prevention. The risk factors for carcinoma cervix and other genital cancers prevalent in Bangladesh should be addressed through behavior change communication (BCC).Effective screening tests should be performed in regular basis.

In Australia, there were 734 cases of cervical cancer in 2005. The number of women diagnosed with cervical cancer has dropped on average by $4.5 \%$ each year since organized screening began in 1991.Regular paps tests prevent more than 1200 women each year from being diagnosed with cervical cancer ${ }^{10}$. Most women who develop cervical cancer have either never had a paps test or did not have them regularly

At present we have sufficient knowledge to prevent at least one third of cancers depending on the availability of resources, early detection and effective treatment of predisposing factors. Further third could be cured with modern amenities. Also there is cancer control strategy in Bangladesh. Government has taken programmatic steps towards developing the cervical cancer screening program. Pilot program of preventing cervical cancer among 50 adolescent girls of 9-13 years of age is started in 2007

\section{Conclusion:}

This study found that majority of women know about the genital cancers and all of them were eager to learn more about genital cancers and their prevention. Cervical and breast cancer screening program is started in Bangladesh. There is also media campaign. We have the infrastructure both Government, private and NGO level. Therefore it can be said that awareness development, supervised screening set up and monitoring throughout the country will reduce the preventable genital cancers in our country.

\section{References:}

1. Kumar P, Malhotra N.."Genital cancers",in Jeffcoats Principles of 
Gynaecology, Seventh Intenational edition(Arnold)2001; 427-39

2. Kent A (2010) HPV Vaccination and Testing. Reviews in obstetrics and Gynaecology 2010; 3(1):33-4

3. Edward P, Armstrong. Prophylaxis of cervical Cancer and related cervical disease; A review of the Cost Effectiveness of Vaccination Against Oncogenic HPV Types. Journal of Managed Care Pharmacy 201016(3): 217-30

4. Fact sheet No. 297: World Health Organisation (February 2006).Cancer"(http://www.who.int/me diacentre/factsheets/fs297/en/index.ht ml).(Accessed on 17.1.11)

5. Akhter PS, Uddin MM, Sharma SK. Patterns of malignant neoplasm - A three year study, Bangladesh Medical journal 1998;27(20):29-32

6. Cervical cancer http// UK.ask.com/wiki/cervical__ cancer (Accessed on 16.1.11)

7. Walboomers JM, Jacobs MV, Manos MM, Bosch FX, Kummer JA, Shah $\mathrm{KV}$, Snijders PJ, Peto J, Meijer CJ, Munoz N. "Human papillomavirus is a necessary cause of invasive cervical cancer worldwide".J. Pathol,1999;189 (1): $12-9$

8. Cervical and Breast cancer screening program standards and guidelines:Department of obstetrics and gynaecology , Bangabandhu Sheikh Mujib Medical University, UNFPA,ISBN: 984-300-000594-8
9. Tiro JA, Meissner HI, Kobrin S, Chollette V.Cancer Epidemiol. Biomarkers Prev.2007;16(2): 288-94

10. Cervical cancer screening. http://www.papscreen. org.au/(Accessed on 17.1.11)

11. Brinton LA, Reeves WC, Brenes MM, Herrero R, de Britton RC, Gaitan E, Tenerio F, Garcia M and Rawls WE. Parity as a risk factor for cervical cancer Am J Epidemiol 1989; 486-96

12. Biswas LN, Manna B, Maiti PK and Sengupta S. Sexual risk factors for cervical cancer among rural Indian women; A case control study. International Journal of Epidemiology 1997; 26(3):492-495

13. Kumar, Vinay, Abbas K;Fausto,Nelson; \&Mitchell, Richard N.(2007) Robins Basic Patology $\left(8^{\text {th }}\right.$ ed.),Saunders Elsvier.718721

14. Campbell S;Monga A. Gynaecology by Ten Teachers $\left(18^{\text {th }}\right.$ ed), Hodder Arnold. ISBN: 0340816627 